Nicolas Farelly

\title{
The Disciples in the Fourth Gospel
}

\author{
A Narrative Analysis of their Faith and Understanding \\ [Die Jünger im vierten Evangelium. Eine narrative Untersuchung ihres Glaubens und ihrer Erkenntnis.]
}

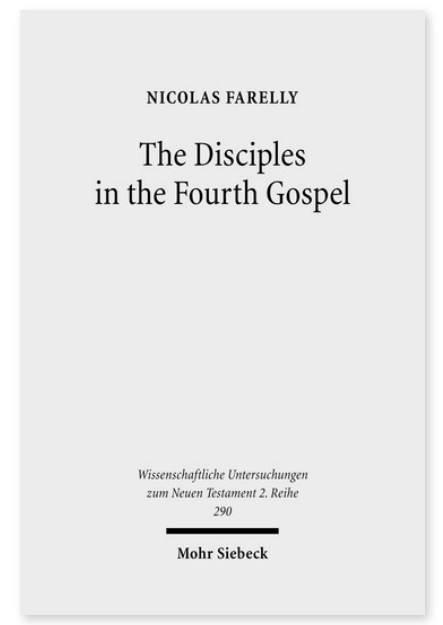

2010. XIII, 260 Seiten. WUNT II 290

ISBN 978-3-16-151633-7

DOI 10.1628/978-3-16-151633-7

eBook PDF 79,00€

ISBN 978-3-16-150583-6

fadengeheftete Broschur 79,00€
Veröffentlicht auf Englisch.

Nicolas Farelly untersucht unter Anwendung der narrativen Analyse die Darstellung der Jünger im vierten Evangelium, dabei stehen ihr Glaube an und ihr Verständnis von Jesus im Zentrum seines Interesses. Nach einer Untersuchung der Jünger als Gruppe konzentriert er sich auf Petrus, Judas, den Lieblingsjünger, Thomas und Maria Magdalena. Mit Hilfe der narrativen Analyse zeigt er auf, dass diese Jünger von Anfang an als gläubig und lebendig dargestellt werden, dass aber deutlich wird, welche Mühe sie haben, die Identität, die Worte und den Auftrag Jesu zu verstehen, bevor dieser in der Schlüsselszene verherrlicht wird. Der Autor zeigt, welche Bedeutung dieser Darstellung der Jünger in der Vermittlung des rhetorischen Ziels des Johannesevangeliums zukommt: Indem der implizite Leser sich mit den Jüngern identifiziert, werden sein Glaube und seine Erkenntnis gestärkt und er wird so darauf vorbereitet, auch Zeugnis abzulegen.

Nicolas Farelly Born 1978; 2009 PhD, University of Gloucestershire, UK; since 2005 director of the Forum Culturel Protestant Compiègne, France; instructor in New Testament Theology, Faculté Libre de Théologie Réformée, Aix-en-Provence, France; instructor in New Testament Theology, Institut Biblique, Nogent-sur-Marne, France.
Jetzt bestellen:

https://mohrsiebeck.com/buch/the-disciples-in-the-fourth-gospel-9783161516337?no_cache=1 order@mohrsiebeck.com

Telefon: +49 (0)7071-923-17

Telefax: $+49(0) 7071-51104$ 